\title{
PROGRAM VIDEO CALL BERBASIS PEER TO PEER MENGGUNAKAN PROTOKOL RTMFP
}

\author{
Nathaniel Gunawan ${ }^{1}$ \\ 22094755@student.ukdw.ac.id
}

\author{
Gani Indriyanta ${ }^{2}$ \\ ganind@gmail.com
}

\author{
Willy Sudiarto R. ${ }^{3}$ \\ willysr@ti.ukdw.ac.id
}

\begin{abstract}
The rapid development of information technology-based communication to encourage the development of video conferencing applications to a variety of media platforms. One of the media that is easily accessible is a web application development based RIA (Rich Internet Application). In this study developed a flash-based video conferencing application to utilize the net class group in ActionScript 3.0 and multimedia protocols RTMFP (Real Time Media Flow Protocol). Streaming video delivery technology requires codecs to be able to transmit video and audio. To find out which one is suitable codec in the development of this application, the analysis is done where appropriate codec for video conferencing on the public network access in terms of the quality of the resulting. The conclusion of the implementation and analysis of three types of audio codecs and codec, is that the codec h.264 and h.264 base profile play a video codec that is suitable for public networks because it produces little noise when there is a lot of movement when compared to the Sorenson video codec.
\end{abstract}

Kata kunci : Video Conference, Flash, RTMFP, Video Codec

\section{Pendahuluan}

Perkembangan VoIP (Voice over Internet Protocol) dewasa ini menjadi semakin dibutuhkan di berbagai bidang. Untuk mengimplementasi teknologi VoIP tersedia berbagai cara serta media, tentu biaya yang dibutuhkan bervariasi. Dalam tahun terakhir ini, banyak perkembangan aplikasi serta teknologi web yang mengunggulkan fitur komunikasi Realtime, salah satunya adalah aplikasi berbasis flash yang mengembangkan protokol untuk keperluan multimedia yaitu RTMFP (Real Time Media Flow Protocol).

Untuk dapat mengatasi kendala-kendala tersebut dapat mengguankan video codec yang mampu mengkompresi data menjadi ringan sehingga beban proses pengiriman tidak terlalu membutuhkan bandwidth yang besar. Tujuan penelitian ini adalah menganalisis video codec apa yang tepat digunakan agar komunikasi berjalan dengan baik tanpa gangguan untuk pengembangan aplikasi video conference berbasis flash.

\section{Landasan Teori}

\subsection{Video Conference}

Video conference adalah proses dimana dua orang atau lebih berkomunikasi dengan video dan audio yang bersifat dua arah. Menurut Gough, jenis video conference diklasifikasikan menjadi 3 yaitu (Gough, 2006):

1) Komunikasi yang hanya melibatkan 2 orang yang berinteraksi satu sama lain dikategorikan personal video conferencing.

\footnotetext{
${ }^{1}$ Teknik Informatika, Fakultas Teknologi Informasi, Universitas Kristen Duta Wacana Yogyakarta

${ }^{2}$ Teknik Informatika, Fakultas Teknologi Informasi, Universitas Kristen Duta Wacana Yogyakarta

${ }^{3}$ Teknik Informatika, Fakultas Teknologi Informasi, Universitas Kristen Duta Wacana Yogyakarta
} 
2) Komunikasi yang melibatkan lebih dari 2 orang serta memiliki fitur seperti file sharing, presentasi, dikategorikan bussiness video conferencing.

3) Komunikasi video conference yang terjadi pada sebuah halaman web dimana hanya satu peserta yang dapat mengirimkan video, sedangkan peserta lain hanya dapat sebagai penonton dikategorikan web video conferencing

\subsection{RTMFP (Real-Time Media Flow Protocol)}

Menurut M. Thornburgh, pada dokumen Adobe's Secure Real-Time Media Flow Protocol, RTMFP adalah protokol komunikasi berbasis end-to-end point pada jaringan internet yang digunakan untuk mengirim data-data multimedia seperti video, audio dan pesan teks secara real-time.

Keuntungan dari implementasi RTMFP adalah dapat mengurangi kebutuhan bandwidth yang digunakan untuk keperluan komunikasi real-time serta permainan multiplayer karena pengiriman data dilakukan secara langsung kepada setiap titik akhir user tanpa melalui server. RTMFP menggunakan layer UDP (User Datagram Protocol) sebagai media dalam mengirimkan data sehingga proses pengiriman data jauh lebih efektif dibandingkan TCP (Transport Control Protocol). (Thornburgh, 2013).

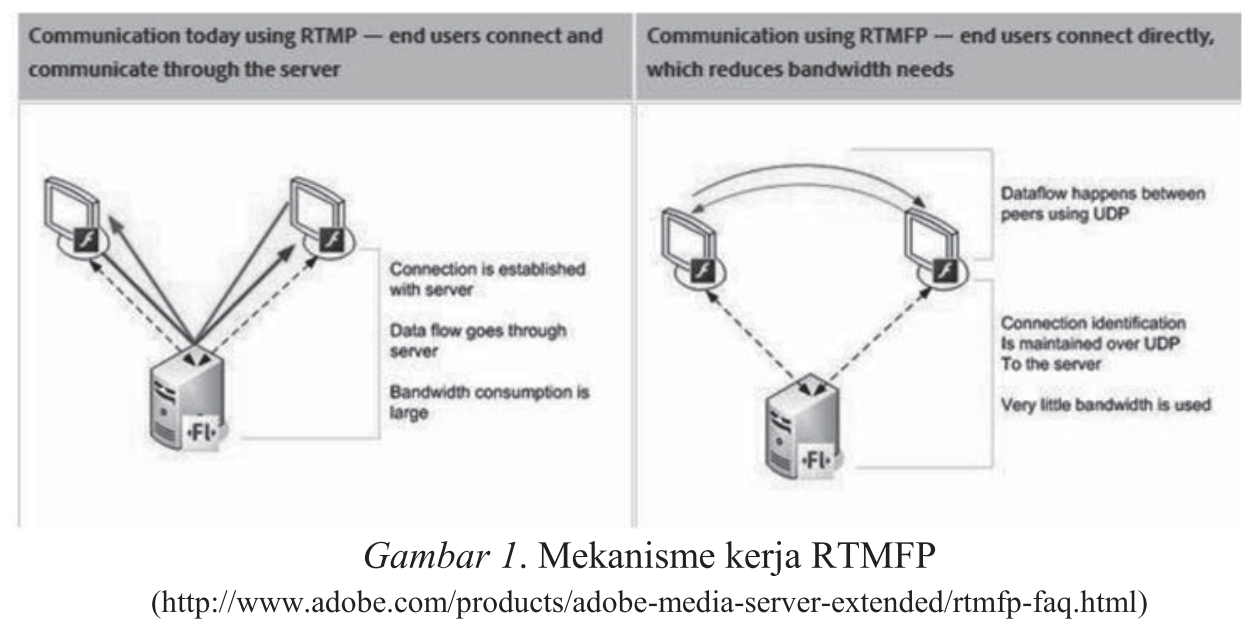

\subsection{Video Bit rate}

Pada buku yang berjudul "Video with Adobe flash CS 4 Professional Studio Technique" karya Reinhardt, Video bit rate adalah besar jumlah data yang dapat ditransmisikan dalam satuan waktu, biasanya dinyatakan dalam satuan kilobits per second (Kbps) atau kilobytes per second (KBps). Jumlah besar kecilnya bit rate dalam video menentukan baik atau buruk kualitas dari sebuah gambar video. Terdapat faktor yang berpengaruh penentuan nilai bitrate antara lain: Frame rate, Frame size dan penggunaan codec compression. Menurut Reinhardt, untuk mendapatkan nilai bit rate yang ideal pada setiap codec dapat dicari dengan menggunakan formula sebagai berikut.

$$
\text { Bit rate }=(\text { width } \times \text { height } \times \text { frame rate }) / \text { codec divisor }
$$

Dengan mengetahui nilai bitrate ideal, maka pertimbangan tersebut dapat disesuaikan dengen konten yang akan disajikan. Selain bit rate, faktor lain yang mempengaruhi kualitas gambar adalah konten dari subyek video yang melakukan pembaharuan piksel pada tiap frame. Selain mengukur bit rate video, perlu dipertimbangkan juga bit rate dari file audio yang dikirim bersama-sama dengan data video. Pada umumnya, ukuran dari audio jauh lebih kecil dibandingkan data video, selain itu proses pengiriman data relatif dari input yang terjadi, artinya apabila tidak terjadi input suara yang harus dikirim, maka sistem tidak akan melakukan pengiriman data audio. (Reinhardt, 2009) 


\section{Hasil dan Pembahasan}

\subsection{Implementasi Sistem}

Sistem video conference dibuat agar dapat diakses dengan jaringan publik sehingga dapat dimungkinkan pengujian dari internet dimana saja. Keseluruhan sistem aplikasi dibuat seperti pada Gambar 2, terdapat server yang memuat layanan RTMFP dan HTTP server, sementara pada sisi client aplikasi flash dibungkus dengan halaman web.

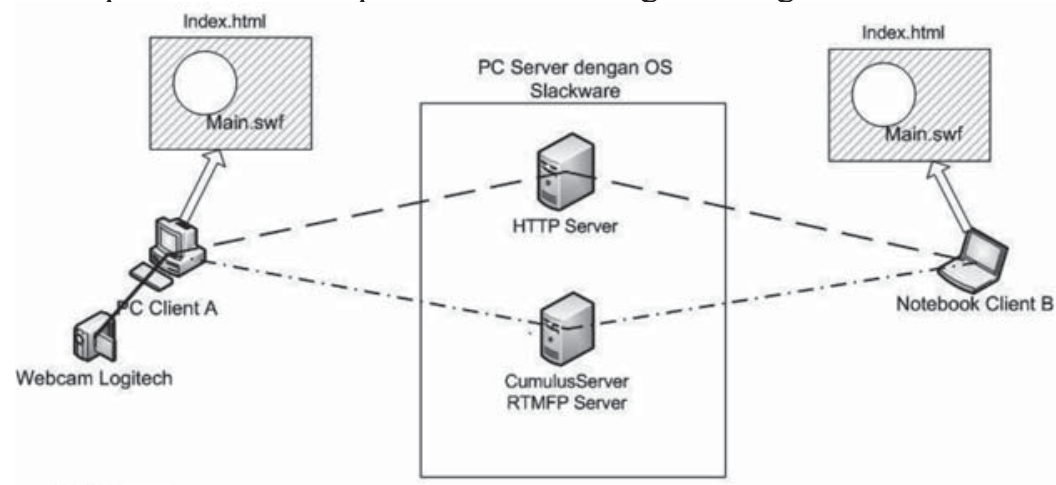

Keterangan :

-. - . - . : Jalur koneksi RTMFP

: Koneksi USB

- - - : Jalur koneksi HTTP

Gambar 2. Desain arsitektur aplikasi video conference

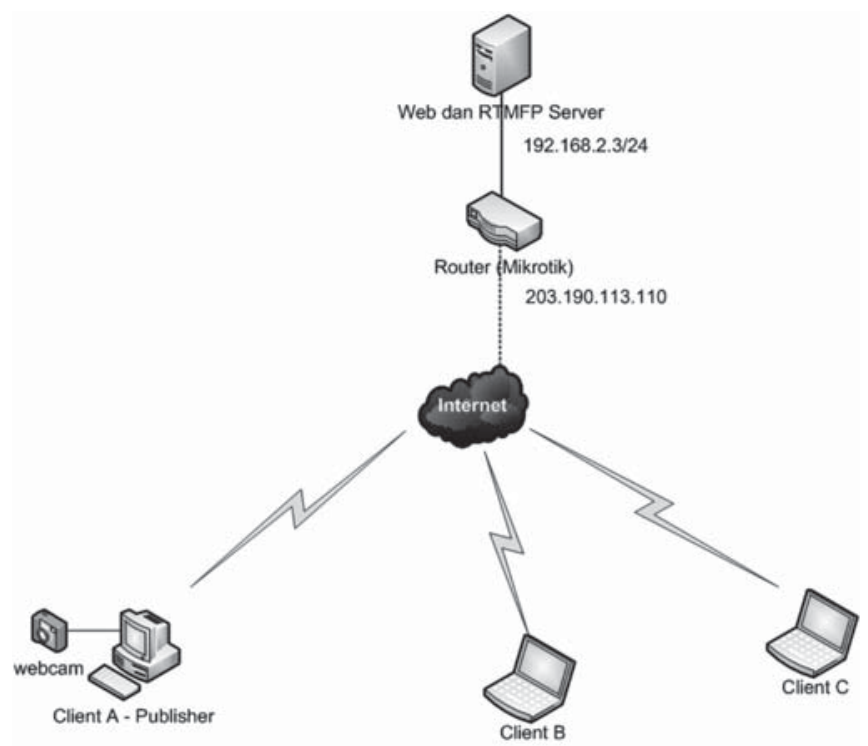

Gambar 3. Arsitektur topologi jaringan

Gambar 3. menjelaskan keseluruhan Arsitektur topologi jaringan yang digunakan, untuk mengimplementasi layanan HTTP dan RTMFP dijalankan dibelakang NAT (Network Address Translator) digunakan konfigurasi port forwarding pada router core mikrotik. 


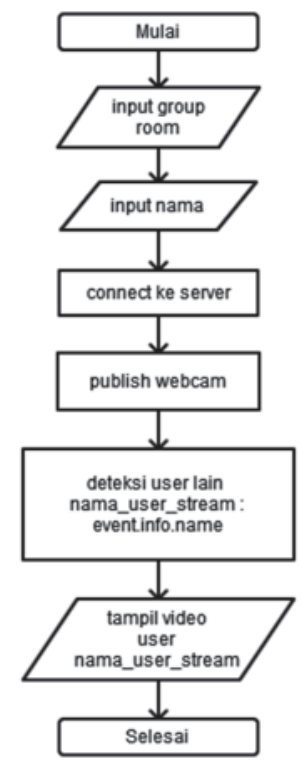

Gambar 4. Diagram alur sistem aplikasi video call

Untuk dapat melakukan komunikasi video conference dimanfaatkan implementasi class API NetGroup dari Actionscript 3.0. Class NetGroup menyediakan layanan P2P grouping pada prokotol RTFMP, dimana setiap user hanya dapat berinteraksi sesuai dengan group yang telah tersetujui. Dalam sistem video conference ini digunakan ukurang bingkai pada setiap video $320 \times 240$ pixel agar hasil input dari kamera dapat ditampilkan maksimal. Penggunaan server RTMFP dalam penelitian ini menggunakan OpenRTMFP Cumulus server. implementasi server digabungkan dengan penyesuaian konfigurasi NAT pada mirkotik. Diagram alur aplikasi dijelaskan seperti pada gambar 3.

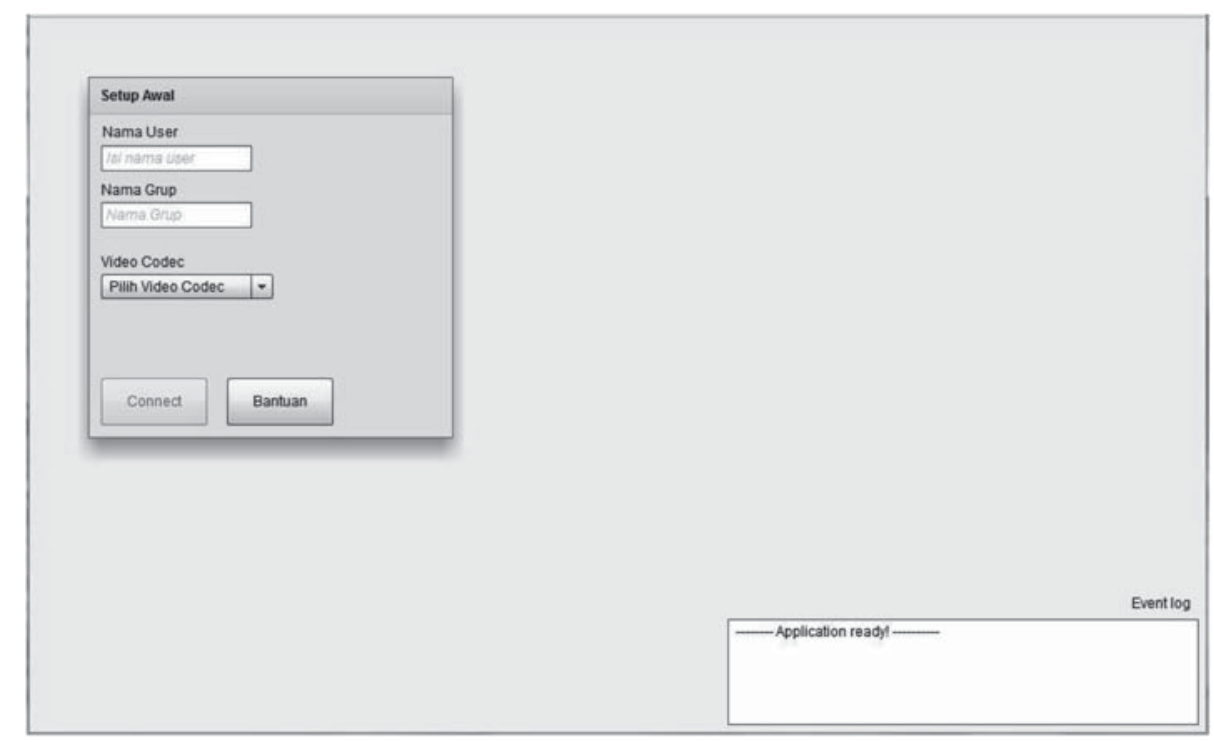

Gambar 5. Implementasi tampilan sistem video call 


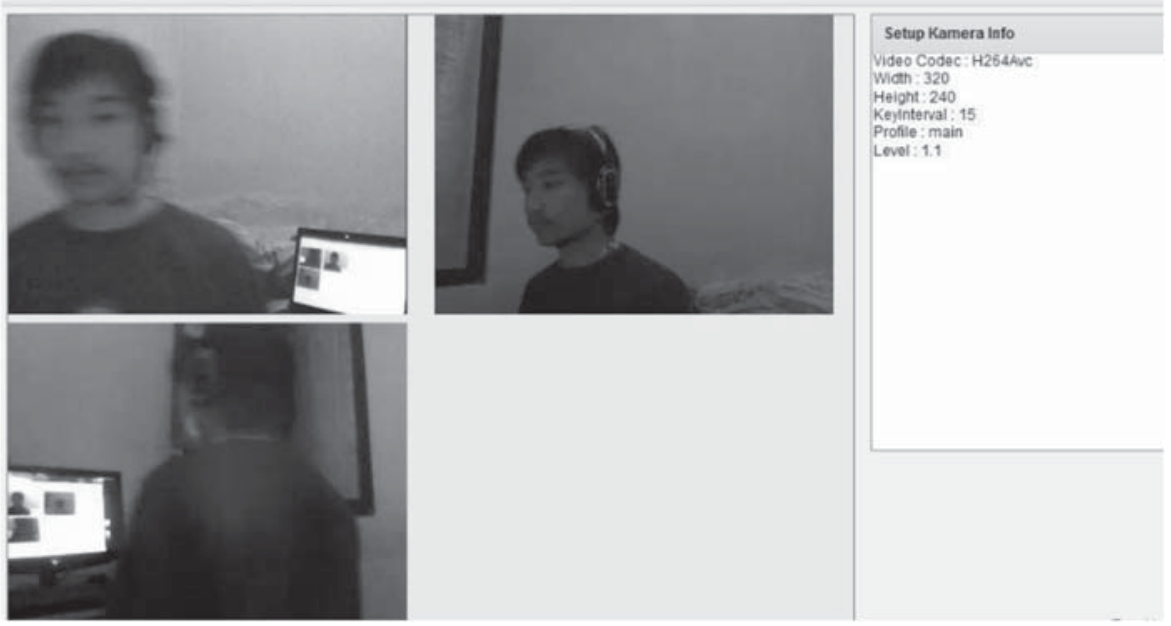

Gambar 6. implementasi video conference

\subsection{Hasil dan Analisa}

Selama proses pengujian aplikasi dilakukan, sistem yang telah di implementasi memiliki kendala apabila diakses melalui jaringan yang menerapkan policy firewall. Dengan memanfaatkan rtmfp checker (http://cc.rtmfp.net) penulis dapat melakukan analisa serta mengetahui apakah pada jaringan yang digunakan untuk mengakses aplikasi mampu menjalankan layanan RTMFP.

Setiap pengujian dilakukan berdasarkan skenario-skenario yang telah disusun. Dengan mencoba aplikasi pada berbagai kondisi serta lingkungan sebagai contoh percobaan di lingkungan ukdw, public hotspot, dan modem GSM. Dari hasil proses implementasi video codec Sorenson, H.264 main, dan H.264 base pada pengujian panggilan dua arah melalui jaringan publik, video codec varian H.264 menghasilkan ketajaman gambar lebih baik dibandingkan sorenson, berikut ini adalah capture gambar dari pengujian panggilan dua arah dengan menggunakan masing-masing video codec.

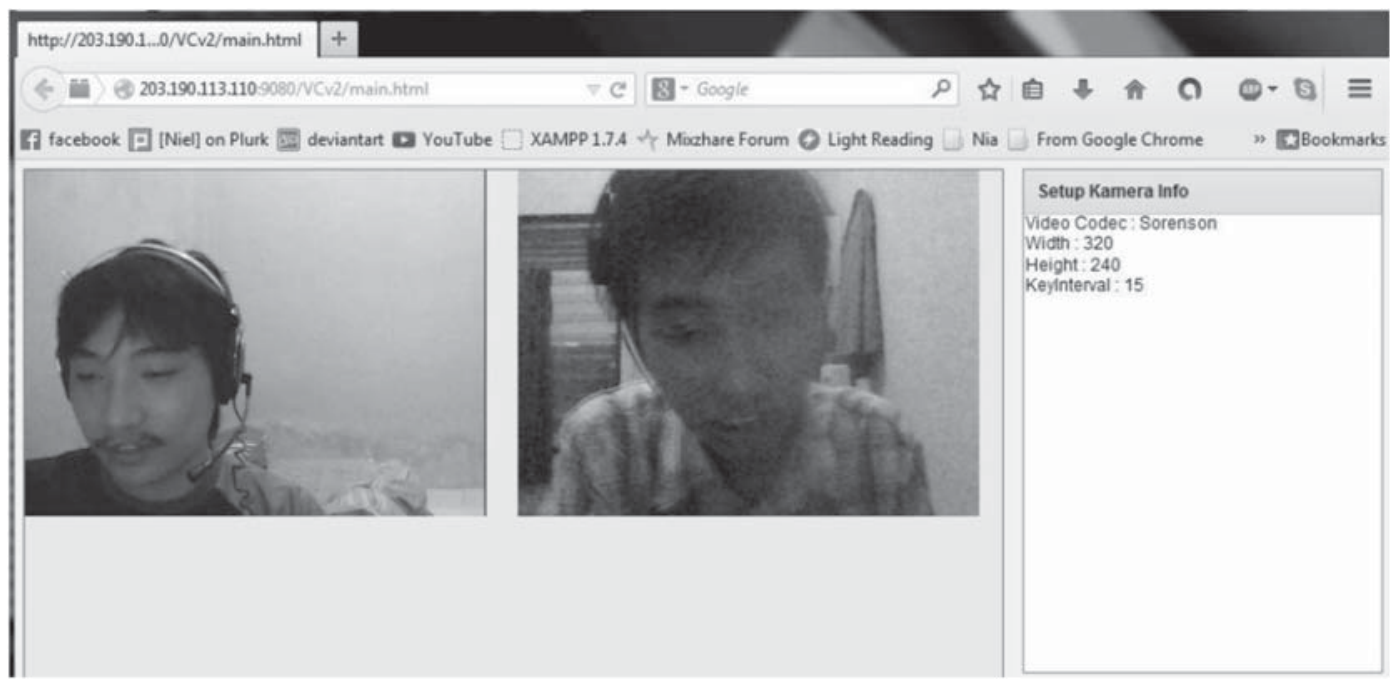

Gambar 7. ketajaman gambar codec sorenson pada video call 


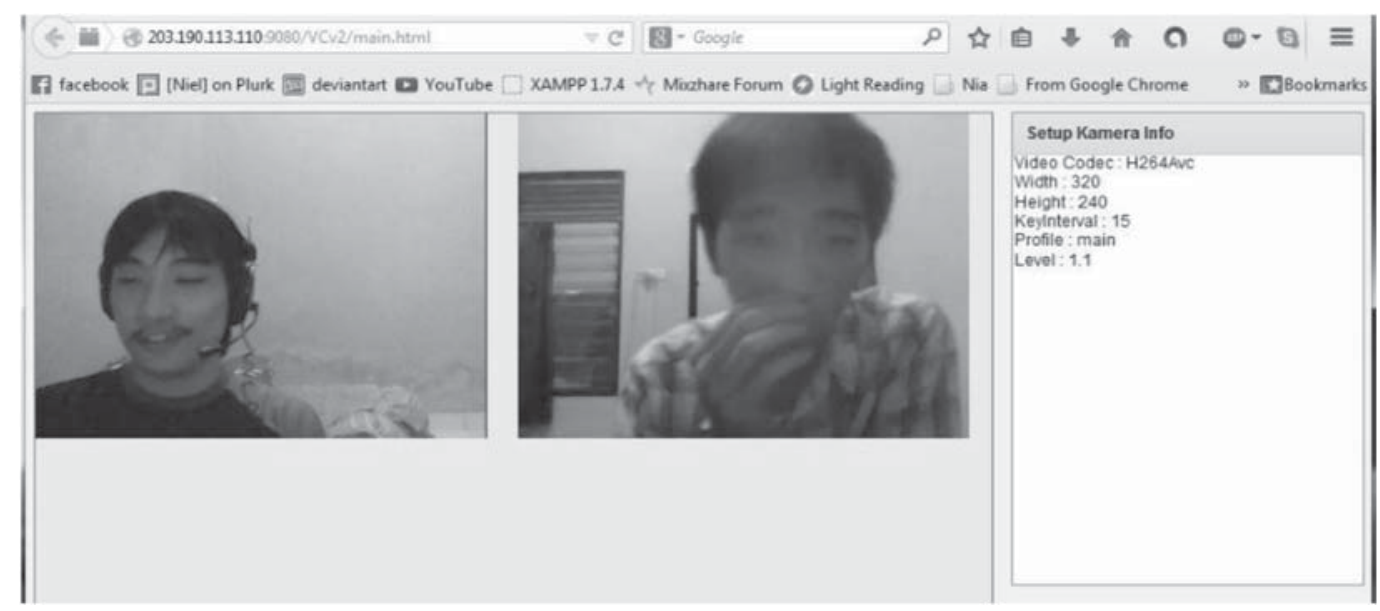

Gambar 8. Ketajaman gambar H.264 main pada video call

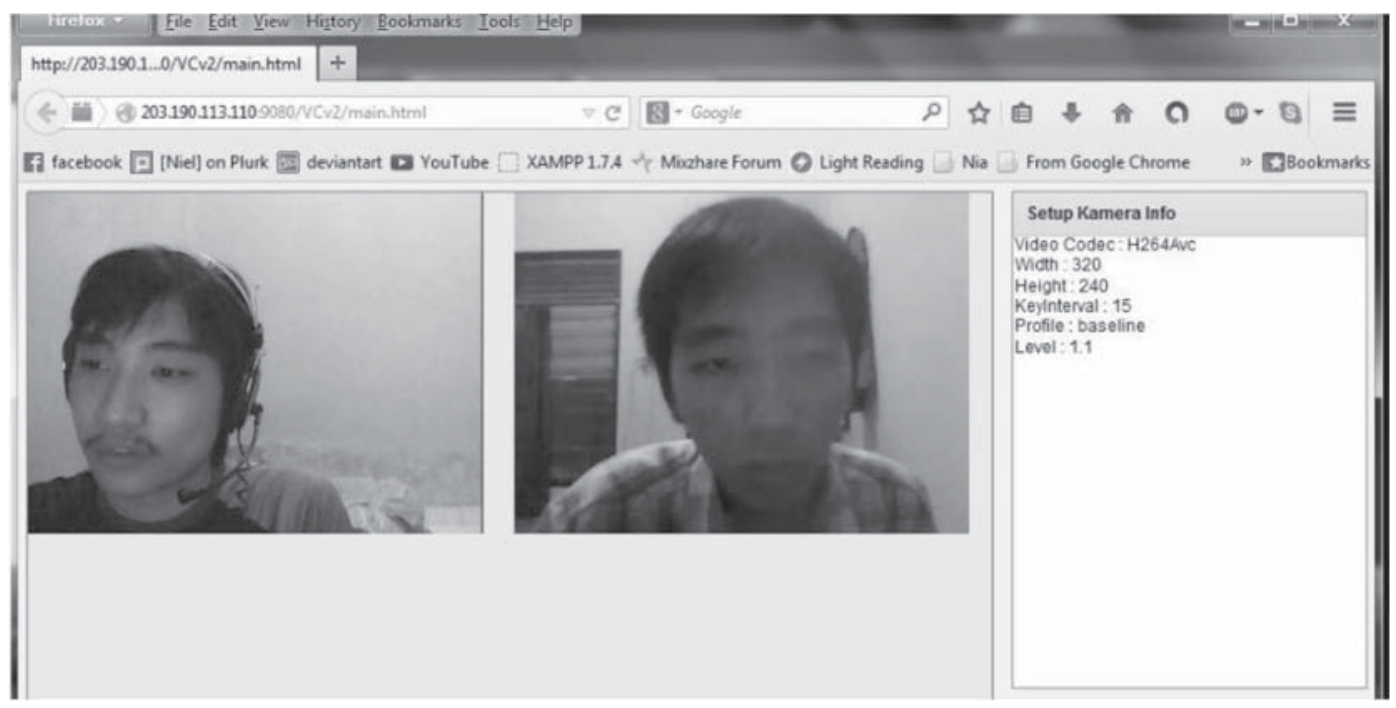

Gambar 9. Ketajaman gambar H.264 base pada video call

Tabel 1.

Hasil nilai troughtput pengujian dua arah

\begin{tabular}{|l|l|l|l|l|l|l|l|l|l|}
\hline \multirow{3}{*}{ Client } & \multicolumn{9}{|c|}{ Rata Rata Troughtput (Mbps) } \\
\cline { 2 - 11 } & \multicolumn{3}{|c|}{ sorenson } & \multicolumn{3}{c|}{ h.264 main } & \multicolumn{3}{c|}{ h.264 base } \\
\cline { 2 - 11 } & 1 & 2 & 3 & 1 & 2 & 3 & 1 & 2 & 3 \\
\hline User A & 2.078 & 0.187 & 2.887 & 0.303 & 0.134 & 0.121 & 0.139 & 0.166 & 0.118 \\
User B & 4.4 & 0.108 & 3.982 & 0.142 & 0.105 & 0.214 & 0.219 & 0.01 & 0.199 \\
\hline Total & 3.239 & 0.1475 & 3.4345 & 0.2225 & 0.1195 & 0.1675 & 0.179 & 0.088 & 0.1585 \\
\hline
\end{tabular}

Untuk mengetahui nilai troughtput pada setiap panggilan dilakukan analisa dengan menggunakan wireshark pada masing-masing client. proses analisa dijalankan selama 60 detik setelah panggilan berhasil dilakukan.

Pada Tabel 1 pengujian 1 dan 3 dilakukan pada lingkungan jaringan dibelakang NAT (Network Address Translator) yang sama, sedangkan pengujian kedua dilakukan dimana setiap client berada pada NAT yang berbeda. Pada codec sorenson troughtput yang diberikan saat menjalankan skenario 1 dan 3 . Nilai yang dihasilkan saat pengujian ke dua lebih kecil dibandingkan pengujian ke satu dan tiga, hal ini karena berdampak saat 
pengiriman data dimana panggilan saat berada pada lingkungan beda jaringan NAT membutuhkan waktu yang lama untuk menampilkan video serta audio. Panggilan yang dilakukan pada saat pengujian berbeda NAT juga mengalami gangguan noise pada suara serta video seperti ditunjukan pada Gambar 6.

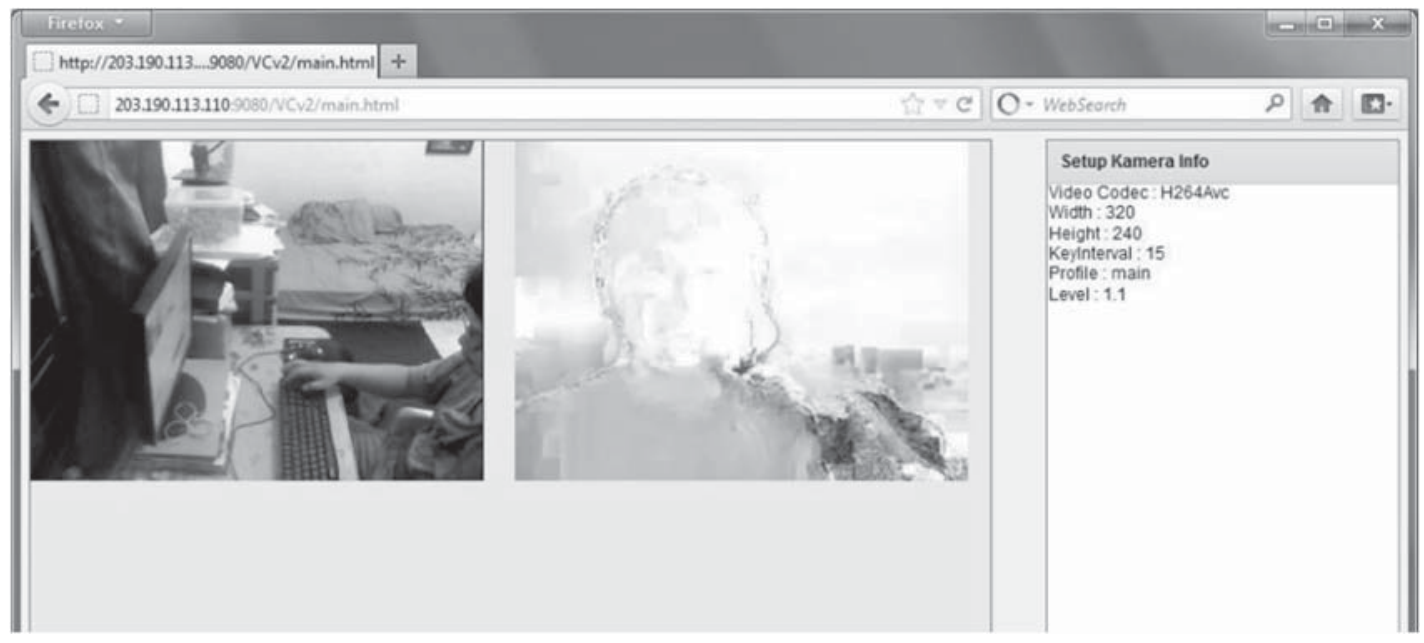

Gambar 9. Hasil capture panggilan pengujian skenario kedua

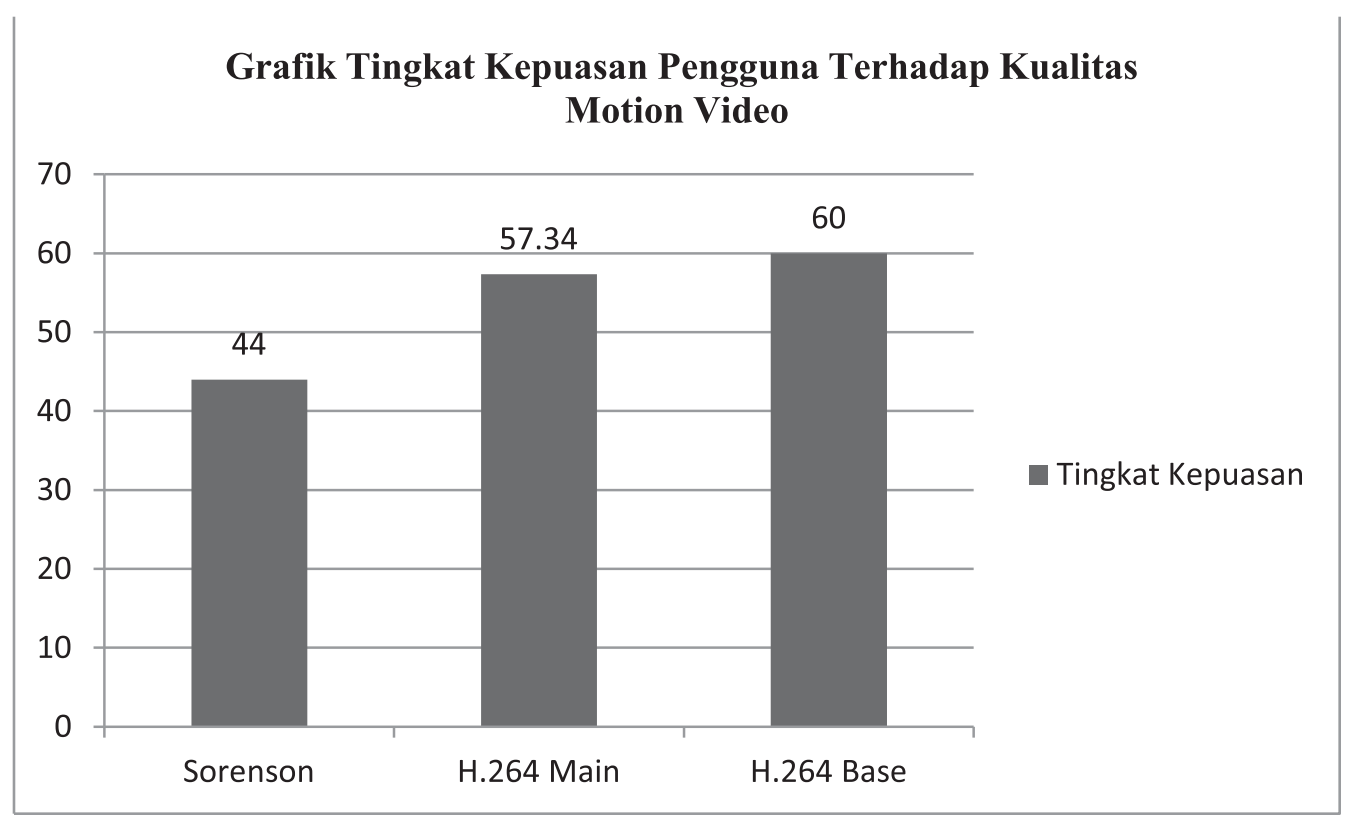

Gambar 10. Grafik kepuasan pengguna terhadap kualitas video codec

Sebanyak 15 responden dipilih sesuai syarat serta kriteria khusus untuk melakukan evaluasi terhadap sistem yang telah dibuat dengan memberi skala nilai 1 hingga 5 poin. Berdasarkan tingkat kepuasan setiap responden yang telah mengevaluasi sistem maka didapat grafik sebagian.

Sebanyak 57.34\% pengguna menyatakan dengan menggunakan video codec H.264 main konferensi video berjalan dengan baik walaupun akan mengalami noise pada gambar apabila terlalu banyak motion yang terjadi. Perbedaan yang tipis ditunjukan pada video codec H.264 base, dimana berdasarkan pendapat pengguna sebesar $60 \%$ kepuasan dalam menggunakan codec H.264 base. Peringkat terakhir dengan nilai tingkat kepuasan pengguna sebesar $44 \%$,dari berdasarkan opini pengguna, video codec sorenson membutuhkan waktu tampil yang lama serta mengalami banyak noise bila terjadi gerakan selama konferensi berjalan.

Untuk pengujian kejernihan kualitas suara yang dihasilkan oleh sistem, codec yang digunakan adalah Speex, dimana Speex digabungkan dengan tiap video codec yang telah ada. Berdasarkan opini serta evaluasi dari partisipan, didapat nilai $68 \%$ pengguna dapat 
menerima output suara yang jelas tanpa mengalami saat codec speex digabungkan dengan video codec H.264 Main. Sedangkan berdasarkan hasil evaluasi responden, kualitas terendah ditujukan pada gabungan sorenson dan speex dengan nilai $45.34 \%$.

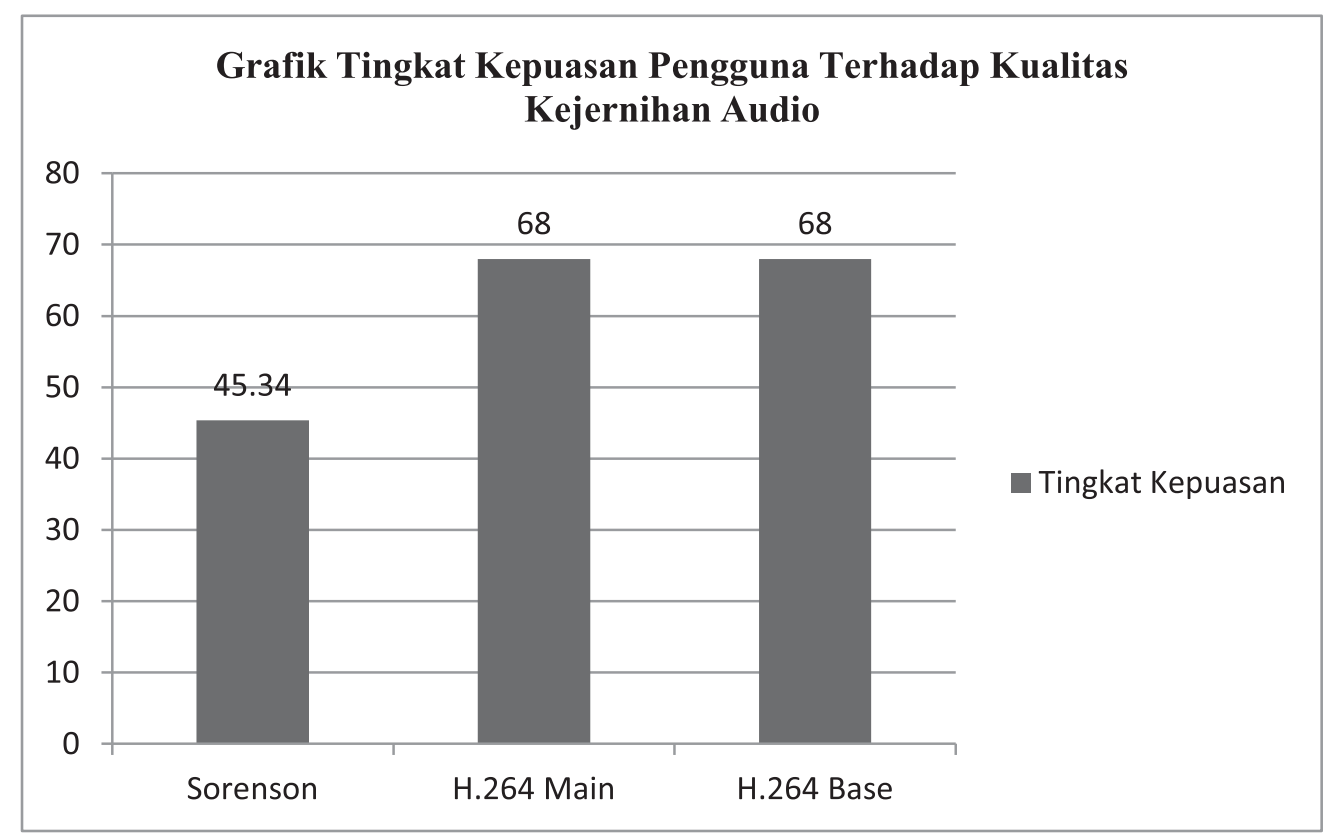

Gambar 11. Grafik kepuasan pengguna terhadap kualitas kejernihan suara

\section{Kesimpulan}

Berdasarkan hasil analisis dan implementasi sistem, maka diperoleh kesimpulan kesimpulan sebagai berikut:

Implementasi video codec H.264 pada pengembangan aplikasi video conference berbasis flash mampu meningkatkan kualitas baik video maupun audio yang diterima pengguna. ini ditunjukan dengan hasil jajak pendapat yang dilakukan kepada 15 orang responden yang telah melakukan percobaan panggilan video call. Codec varian H.264 mampu memberikan hasil terbaik ditunjukan sebesar $57.34 \%$ responden puas terhadap kualitas dari codec h.264 main, serta $60 \%$ untuk h.264 base.

Penggabungan audio codec Speex dengan video codec varian H.264 main dan base memberikan hasil suara yang jelas jika dibandingkan saat menggunakan codec sorenson . kesimpulan tersebut ditunjukan berdasarkan jajak pendapat dari 15 partisipan pengujian menyatakan puas dengan hasil suara saat melakukan panggilan dengan menggunakan video codec H.264 main sebesar $68 \%$ dan 68\% untuk H.264 base.

\section{Daftar Pustaka}

Reinhardt, R. (2009). Compression and Encoding Primer. Di Susan Rimerman (Ed). Video with Adobe Flash ${ }^{\circledR}$ CS4 Professional Studio Technique (Hal 54-60). Berkeley: Peachpit.

M.Thornburgh. (2013). Adobe's Secure Real-Time Media Flow Protocol. Diakses pada 11 Febuari 2013 dari http://tools.ietf.org/html/draft-thornburgh-adobe-rtmfp10\#section-3.5.1.1

M. Gough. (2006). Video Conferencing over IP: Configure, Secure, and Troubleshoot. Rockland: Syngress. 